Resenha

\title{
A crise na União Europeia \\ O futuro como desafio
}

\section{The crisis in the European Union}

The future as a challenge

Sidnei Ferreira de Vares*

\section{$\underline{\text { Resenha de: }}$}

BECK, Ulrich. A Europa alemã: a crise do euro e as novas perspectivas de poder [tradução de Kristina Michahelles]. Rio de Janeiro: Paz e Terra, 2015. 126p.

Ulrich Beck nasceu em 1944 na Pomerânia, divisa entre Polônia e Alemanha. Foi professor emérito de sociologia da Universidade de Munique e também lecionou em Harvard e na London School of Economics. Foi autor de alguns livros importantes, entre eles Sociedade de risco: rumo a uma outra modernidade (Beck, 2010). Infelizmente, o sociólogo faleceu no início de 2015.

A Europa alemã, um de seus últimos trabalhos, constitui um ensaio sobre a situação atual da Europa, sobretudo após a crise financeira iniciada em 2008, cujos efeitos perniciosos a maior parte dos países-membro da União Europeia - e da zona do euro - acusaram em suas economias domésticas. O trabalho contém uma breve apresentação à edição brasileira, escrita por Bruno de Moura Borges, doutor em Ciência Política pela Duke University (EUA). Quanto ao texto de Ulrich Beck, este se divide em três capítulos todos eles contendo intertítulos - precedidos de um prefácio e de uma breve introdução, e é claro, ao final, sucedidos de uma conclusão. Por se tratar de

\footnotetext{
*Doutor e mestre em Educação pela Universidade de São Paulo (USP, São Paulo, SP, Brasil), professor dos cursos de História, Filosofia e Pedagogia do Centro Universitário Assunção (UniFAI) e do curso de História do Centro Universitário Sant'Anna (UniSant'Anna), ambos em São Paulo, SP, Brasil<vares@usp.br>.
}

Civitas, Porto Alegre, v. 16, n. 3, p. 455-462, jul.-set. 2016 
um assunto extremamente recente, o autor, como o leitor certamente notará, faz uso frequente de matérias e artigos jornalísticos para fundamentar suas posições, mas, ainda assim, não dispensa a literatura especializada, sendo possível localizar ao longo do ensaio referências a diversos estudos sobre o assunto.

Na Apresentação à edição brasileira, Bruno de Moura Borges procura dar ao leitor uma visão panorâmica sobre a trajetória de Ulrich Beck. Borges fornece as credenciais do sociólogo alemão, destacando-o como "um dos principais estudiosos da modernidade", cujos trabalhos sociológicos têm contribuído no sentido de fornecer "alguns parâmetros fundamentais à discussão contemporânea sobre o mundo atual e os desafios do século 21" (p. 9). Borges também destaca o termo "sociedade de risco" criado por Beck, através do qual o sociólogo demonstra uma das principais características da modernidade tardia: "viver sob a égide do risco constante cria um sentido de angústia e de emergência na vida cotidiana que se traduz na maneira como criamos e mantemos as instituições atuais" (p. 9). Aliás, como ressalta Borges, o livro Sociedade de risco: rumo a uma outra modernidade, onde o conceito aparece pela primeira vez, tornou-se a principal obra de Beck, e uma das principais obras de teoria sociológica para se compreender a contemporaneidade. O cuidado com que Borges apresenta o conceito de "sociedade de risco" tem uma razão de ser, a saber, ele estaria no centro de seu ensaio A Europa alemã, escrito no auge da crise financeira grega, em 2012. Naquele momento, não foram poucos os que previram que a zona do euro poderia se desfazer em "efeito dominó", levando consigo não só a Grécia, mas também a União Europeia. Contudo, se em apenas dois anos a situação de risco agudo parece ter sido mitigada, a Europa não passa por um bom momento. Pelo contrário, a agudização da crise só fez evidenciar a emergência de um novo quadro político marcado pela influência da Alemanha sobre o continente europeu. A Alemanha tornou-se, enfim, imperial, e todos os olhos se voltam para Ângela Merkel. Porém, o argumento de Beck é de que a estratégia intencional da chanceler alemã é a de "empurrar com a barriga" a crise institucional e política enfrentada pela Europa. A chamada "política de austeridade", velha conhecida de países como Grécia, Portugal, Espanha e Itália não surtiu qualquer efeito no sentido de impulsionar a economia desses países. Ao contrário, assistimos à falência de grandes bancos, o aumento das taxas de desemprego entre as faixas mais jovens da população ou o reflorescimento de partidos de orientação fascista, declaradamente racistas, os quais, cada vez mais, alcançam votações expressivas para os parlamentos nacionais. Tudo isso, é claro, não só põe em risco o pacto social-democrata que tem no estado de bem-estar social 
sua maior bandeira, como também demonstra os limites da democracia representativa baseada no estado-nação, em dar respostas aos dilemas de cada país do bloco, expondo a incapacidade dos "arquitetos da Europa", isto é, dos políticos e técnicos, em oferecer soluções. O resultado disso: a crescente divisão, primeiro entre países da zona do euro e os de fora dela, segundo entre países credores e devedores dentro da própria zona do euro, e em terceiro a divisão em uma Europa de duas velocidades diferentes. E eis que a própria Alemanha corre o risco de ser engolida pela crise que retarda em combater. É a partir desses elementos que Beck, afirma Borges, coloca uma questão crucial: é possível superar o estado-nação e pensar a política sob uma nova ótica, europeia e transnacional?

Em seu curto Prefácio, Ulrich Beck faz uma afirmação contundente: a Europa se tornou alemã. Tal fato suscita uma série de questões: como isso se deu? Quais as consequências? Quais os futuros cenários? O autor apresenta assim a intenção de seu ensaio: propor uma nova interpretação da crise, analisando a fundo as notícias dos noticiários televisivos, manchetes de jornais etc., questionando-as dentro de seu contexto, tentando, pois, tornar visíveis as transformações e a nova paisagem do poder face à crise financeira.

Logo na Introdução, intitulada A Alemanha ante a decisão sobre o 'ser ou não ser' da Europa, Ulrich Beck demonstra, através de uma questão, o paradoxo europeu: o que ocorre quando uma democracia determina os rumos de outra democracia? Ora, é exatamente isto que vem ocorrendo na Europa, em especial na Grécia, que, necessitando do dinheiro alemão, vê-se impelida a aceitar as determinações do governo alemão. Na prática, é o parlamento alemão, e não o grego, que decide o destino da Grécia. Esse esvaziamento de soberania nacional suscita uma série de questões: com que direito a Alemanha faz isto? Qual é a legitimidade democrática desse tipo de interferência? As questões econômicas devem ser priorizadas face às questões políticas? Em outras palavras, o peso da dívida justificaria que a Grécia, berço da democracia, perca o seu direito à autodeterminação democrática? Por que tamanha interdição de uma democracia por outra não chama mais a atenção da opinião pública? A União Europeia abrange 27 países-membros, governos, parlamentos. Conta com um parlamento, uma comissão, um tribunal de justiça, um alto representante para negócios externos etc. Mas a crise financeira e do euro impulsionou a Alemanha para a posição de potência decisiva, a única com poderio econômico para assumir a "responsabilidade" pela Europa. O dilema alemão reside em ressuscitar a utopia de uma Europa política contra todas as resistências ou manter a política de empurrar com a barriga. Para Beck, o momento decisivo chegou, e embora a opinião pública não verbalize 
isso, contrariamente do que afirmam os observadores internacionais, o dilema está posto: se a Alemanha adotar uma política financeira que leve o euro ao fracasso, será a culpada; por outro lado, só a Alemanha pode assumir a responsabilidade pela Europa. Eis o que Beck denomina de "Europa alemã".

No primeiro capítulo, Como a crise do euro dilacera - e une - a Europa, Ulrich Beck inicia expondo o contexto de surgimento da União Europeia - da agonia da guerra e em resposta aos horrores do holocausto - para logo em seguida afirmar que, hoje, a geração que vive a crise, também experimenta o seu "fado europeu". O número de jovens com menos de 25 anos desempregados ou com contratos de trabalho temporários é recorde em países como Itália, Grécia, Espanha e Portugal. Não por acaso, a maior parte dos protestos por justiça social advém da "geração facebook". A juventude externa toda a sua raiva contra as políticas que salvam bancos e joga no ralo o futuro das novas gerações. E assim a Europa expõe os seus novos contornos; um continente dividido entre países do norte e do sul, países credores e devedores. Medidas para salvar a zona do euro são tomadas sem que os principais afetados sejam ao menos consultados. Daí um paradoxo se impõe: o que fazem os salvadores, se aqueles que precisam ser salvos não querem? Ou pelo menos não querem desta forma, apresentada por seus próprios governos como "a única alternativa"? Segundo Beck, no futuro haverá muitas europas na Europa. Uma delas, assevera, será a "Europa de baixo", "a Europa dos cidadãos, que talvez nem saibam (ou não queiram saber) que são cidadãos da Europa" (p. 26), na qual a atmosfera é um misto de medo, insegurança e indignação, conquanto falte às pessoas palavras para externar seus sentimentos. Esta ignorância generalizada faz parte da própria dinâmica à qual as sociedades ocidentais estão entregues. É isto que o autor chama de "sociedade de risco", uma sociedade onde tudo pode acontecer. É claro que a União Europeia deseja provar para si e para o mundo que é capaz de enfrentar a pior crise da sua história. Também é evidente que, ao longo de seus cinquenta e cinco anos de existência, considerando o Tratado de Roma, que instituiu a comunidade econômica europeia, muitas coisas foram conquistadas, como, por exemplo, a dissolução de rivalidades históricas entre países vizinhos, a ampliação da liberdade política e um padrão de vida superior a outras partes do mundo. Entretanto, para Beck, a Europa vive seu pior momento, já que, como dizia Gramsci, a velha ordem morreu e a nova ordem ainda não conseguiu nascer. Por isso, apesar de toda perplexidade, medo e frustração, há um anseio por transformação que não pode ser ignorado. Porém, "o olhar econômico é social e politicamente cego", pois "os conselhos econômicos que dominam o debate se baseiam em um ‘analfabetismo' sociopolítico" (p. 34), iludindo a opinião pública e os políticos 
com suas propostas míopes e equivocadas - como no caso dos que defendem a saída da Grécia da zona do euro - sem mensurar os custos sociais e políticos delas resultantes. Isto porque existem épocas em que se faz uma "política menor", que obedece a regras, e existe um tempo para uma "política maior", isto é, uma política que modificas as regras. O tempo de crise atual, conforme salienta o sociólogo, é um tempo que requer mudanças. Mas estas, todavia, não podem ser empreendidas de maneira isolada ou assimetricamente. Sobretudo em um mundo globalizado é mister que todos os envolvidos participem, dêem a sua contribuição, escutem e sejam escutados. Contudo, enganam-se aqueles que pensam que a crise é eminentemente econômica. Trata-se também de uma crise de valores, onde a xenofobia e a violência tornam-se riscos reais, sobretudo por conta da "arrogância" com que os europeus do norte tratam os do sul. Prova disso é o tratamento dispensado à Grécia, berço da cultura ocidental, mas hoje reduzida a um país supostamente formado por um bando de preguiçosos e indisciplinados.

No segundo capítulo, As novas coordenadas do poder na Europa e as origens da Europa Alemã, o mais longo do livro, Ulrich Beck situa os entraves que a "crise europeia" impõe aos intelectuais. Entre os que investigam a "reprodução" da ordem social e os que se dedicam a compreender sua "transformação", o autor - na nota de rodapé 23 - afirma que sua teoria da sociedade de risco se concentra nos casos de "exceção", isto é, onde o risco abre a sociedade e a política para possibilidades inimagináveis e de efeitos globais - como no caso da usina de Chernobyl ou do ataque às torres gêmeas nos EUA - o que exige do pesquisador novas categorias de pensamento e da ação, que transcendam a dimensão do estado nacional. Beck aproveita para demonstrar como o discurso da catástrofe - que se identifica com ameaças futuras - gera uma espécie de paralisia. O caso do suposto colapso da União Europeia é emblemático nesse sentido. O pânico das pessoas, a falta de perspectiva, simplesmente oculta do rol de possibilidades o "princípio de esperança" inerente a uma sociedade de risco. Há, aqui, um ponto essencial na argumentação do autor: "o risco arranca as pessoas de seu dia a dia e os políticos das chamadas restrições objetivas" [...]. [Em outras palavras], "o risco é algo que abre os olhos das pessoas, mas ao mesmo tempo desperta esperanças por uma saída positiva” (p. 49). Na perspectiva do autor, a União Europeia, que vive hoje o discurso da ameaça, tem dois cominhos possíveis: (a) rumar em direção à cooperação democrática ou (b) rumar em direção a sua derrocada. A esse respeito, observa Beck, a "união bancária" é uma das "novas expressões da esperança" com que os "arquitetos da Europa" acenam a fim de configurar para o futuro político. Porém, reside aqui um dilema, pois, 
para que a "união bancária" se estabeleça é preciso que os governos nacionais se dobrem frente à implantação de uma "nova autoridade europeia" calcada em uma regulamentação transnacional, porém, a aceitação de tal condição, em termos práticos, significaria submeter a autonomia nacional a uma esfera de poder maior, transnacional, o que invadiria os sistemas jurídicos locais. $\mathrm{O}$ dilema, então, pode ser assim resumido: mais Europa ou mais estado nacional? Entretanto, essa "lógica do risco" em nada se aproxima da "lógica da ameaça da guerra". A transformação política que a Europa atual necessita não se assenta na defesa militar das fronteiras ou de subjugar inimigos, ou seja, na velha lógica amigo/inimigo, mas sim no esforço de cooperação, redirecionando "o olhar para a explosão da pluralidade do mundo" (p. 64). Como esclarece o sociólogo, "o novo imperativo, a nova racionalidade histórica agora são a comunicação e a cooperação além das fronteiras, a inclusão das diferenças nacionais, religiosas etc., a disposição de se aceitar mutuamente. Em suma: a superação da imagem do inimigo se torna razão de estado" (p. 66). Todavia, as dificuldades para uma saída racional estão postas. A influência de alguns países como França e Alemanha é notória. Durante algum tempo, a dupla "Mercozy" (Merkel-Sarcozy) intensificou a divisão entre os países do euro e os demais países da União Europeia, a divisão entre países credores e devedores - muitas vezes atentando contra a soberania destes últimos - e, igualmente, a divisão em relação à velocidade do processo de integração política, discriminando áreas mais rápidas de áreas mais lentas. Beck afirma ser possível identificar facilmente essas divisões, hoje centrada quase que exclusivamente na Alemanha. Não por acaso Merkel, para o sociólogo, tornou-se "Merkiavel". A brincadeira tem uma razão de ser. Maquiavel, o famoso filósofo político italiano, teve um papel importante no sentido de pensar a relação entre poder, história, virtude e circunstância. Na leitura de Beck, há na teoria política de Maquiavel um ponto de aproximação com a teoria da sociedade de risco, isto por que em ambas, face às catástrofes ameaçadoras, abrem-se possibilidades (ocassiones), que um governante virtuoso pode ou não aproveitar. Foi isso que Angela Merkel fez segundo o autor: aproveitou a situação de crise para reestruturar as relações de poder na Europa. Isto porque a chanceler alemã se tornou uma espécie de "rainha não coroada da Europa", jogando, como o príncipe de Maquiavel, não para salvar os países devedores, mas para mantê-los divididos, pois disso resulta o protagonismo econômico e político alemão. E assim, combinando fortuna e virtù, Merkiavel conseguiu aproveitar a oportunidade histórica engendrada pela crise na zona do euro, beneficiando-se tanto na política interna quanto na externa, além de domar, sem hesitação, qualquer bastião de resistência. Como deixa claro o autor: 
O novo poder alemão na Europa não se baseia, portanto, na violência como razão última, com ocorreu em outras épocas. Já não necessita de armas para subjugar outras nações à sua vontade. Por isso, falar de Quarto Reich parece absurdo. O poder fundado na economia é muito mais versátil. Não é preciso invadir um país, mas mesmo assim, ele é onipresente. Seu potencial de extorsão não nasce da lógica da guerra, e sim da lógica do risco, mais precisamente: a lógica da ameaça do colapso econômico (Beck, 2015, p. 83-84)

Com efeito, a "Europa alemã" de Merkiavel evidencia uma nova situação de poder: a imposição das regras de austeridade econômica prescritas pelos alemães, que forçam os países devedores se submeterem, e a consequente derrocada social de regiões inteiras.

No terceiro e último capítulo, Um pacto social para a Europa, Ulrich Beck lança algumas questões importantes: estaríamos nos movendo em direção a uma nova era pós-europeia? A União Europeia estaria rumando a futuro do século 19, tornando-se um aglomerado de nações rivais? Ou será que ela marcha no rumo de uma sociedade transnacional? Para o autor, há indícios de que se trata de uma "sociedade europeia dos indivíduos", isto é, uma sociedade formada a partir de várias sociedades democraticamente constituídas. As novas gerações, afirma Beck, são prova disso. Os jovens europeus se definem, primeiramente, por sua nacionalidade e, depois, pelo fato de viverem na Europa. Esses jovens transitam com naturalidade pelo território europeu e vivenciam a Europa em suas múltiplas possibilidades, permeando fronteiras diferentes das suas fronteiras de origem, envolvendo-se com outras línguas, culturas, costumes, sistemas jurídicos etc. Inspirado em Rousseau, Beck afirma que a Europa precisa de um "novo contrato social", capaz de proteger essa liberdade cosmopolita tanto do nacionalismo ortodoxo quanto do capitalismo de risco. Para tanto, esse novo contrato social deve projetar uma utopia realista, baseada na seguridade social - sem cair numa espécie de lembrança nostálgica do welfare state ou na febre reformista neoliberal. Isso só será possível, porém, caso a democracia seja pensada de baixo para cima, estimulando os indivíduos a se descolarem de sua realidade geográfica nacional, experienciando as angústias, as dificuldades e as esperanças dos europeus que vivem em outros países. Para o autor, esse processo traria uma consciência europeia, que, somada a uma mudança institucional, poderia estabelecer as bases para uma nova sociedade transnacional europeia, resguardando os direitos individuais e democráticos. Para aqueles que acham esta solução é ingênua e idealista, Beck faz a seguinte afirmação: 
Sim, essa crise leva a uma reavaliação do realismo. O que até agora era tido como "realista" se torna ingênuo e perigoso, pois leva em conta a ruptura. E o que era dito como ingênuo e ilusório se torna "realista", porque tenta evitar a catástrofe e, além disso, melhorar o mundo (Beck, 2015, p. 118).

Não obstante, é acrescendo ao esperançoso verso de Hölderlin, “onde existe perigo, ali também germina a salvação", que Beck fecha o livro com a seguinte sentença: "onde existe o perigo, ali germinam os mecanismos de salvação".

O livro de Ulrich Beck é de fácil leitura. O texto é bastante claro, atrativo e muito bem escrito. A erudição do autor é visível, sobretudo no que se refere às suas incursões na história europeia. Mas é a sua capacidade de análise do presente o que mais chama atenção. O modo como o sociólogo aborda a crise - como porta de entrada para uma nova configuração política e social - é bastante convincente. Embora o livro tenha sido escrito e publicado em 2012 (no Brasil foi publicado em 2015), a recente resistência grega à força política e econômica germânica parecer reforçar a análise empreendida pelo autor. Ademais, conquanto não se utilize de categorias derivadas da teoria social clássica, em especial a marxista, o emprego de noções tais como as de utopia, resistência, mudança, consciência etc., deixa transparecer sua vinculação teórica, ligeiramente à esquerda. Certamente o ponto forte do livro diz respeito à forma como Beck inverte a relação real/ideal. Em outros termos, a frase eternizada em uma pichação nos muros da Sorbonne, em maio de 1968, poderia servir de epígrafe ao livro: "Seja realista, peça o impossível!". Outra Europa não só é possível, mas também desejável. Nesse sentido, se a crise constitui um risco, os europeus precisam se arriscar. É este o desafio que urge: inércia ou mudança? Eis o ser ou não ser da consciência.

Autor correspondente:

Sidnei Ferreira de Vares

Rua São Sabino, 168 - Vila Diva

03375-080 São Paulo, SP, Brasil

Recebido em: 8 set. 2016.

Aprovado em: 12 set. 2016. 